Supporting Information for:

\title{
Well-Ordered Inorganic Nanoparticle Arrays Directed by Block Copolymer Nanosheets
}

\author{
Nan Yan ${ }^{1}$, Xuejie Liu ${ }^{1}$, Jintao Zhu ${ }^{2, *}$, Yutian Zhu ${ }^{1,3, *}$, and Wei Jiang ${ }^{1}$ \\ ${ }^{1}$ State Key Laboratory of Polymer Physics and Chemistry, Changchun Institute of \\ Applied Chemistry, Chinese Academy of Sciences, Changchun 130022, China \\ ${ }^{2}$ Key Laboratory of Materials Chemistry for Energy Conversion and Storage, Ministry of \\ Education (HUST), School of Chemistry and Chemical Engineering, Huazhong \\ University of Science and Technology (HUST), Wuhan 430074, China \\ ${ }^{3}$ College of Materials, Chemistry and Chemical Engineering, Hangzhou Normal \\ University, Hangzhou 311121, China \\ *Corresponding authors: E-mail: jtzhu@mail.hust.edu.cn (J. Z.); \\ ytzhu@ciac.ac.cn (Y.Z.)
}

\section{Contents:}

Figures S1-S12 Additional figures for the BCP nanosheets.............. Page S2-S9

Tables S1-S2 Tables for AuNPs and distribution in polymer sheets.........Page S9-S10 


\section{SUPPORTING FIGURES:}
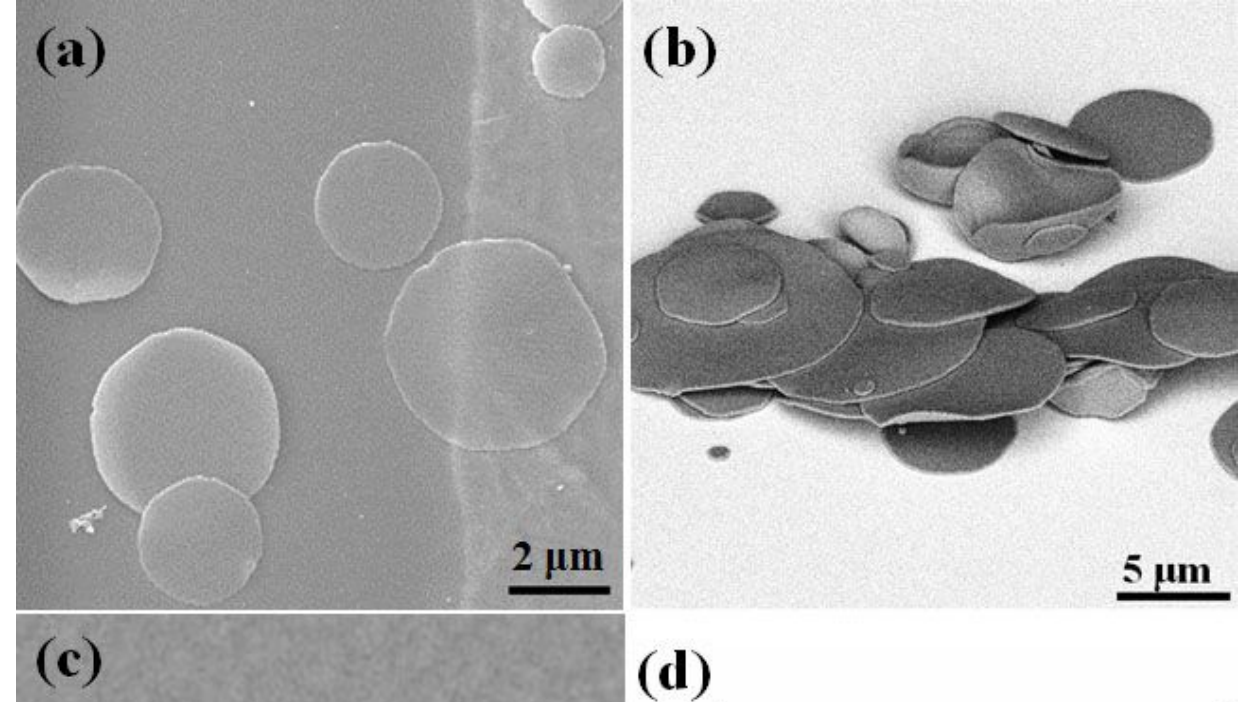

\section{(d)}

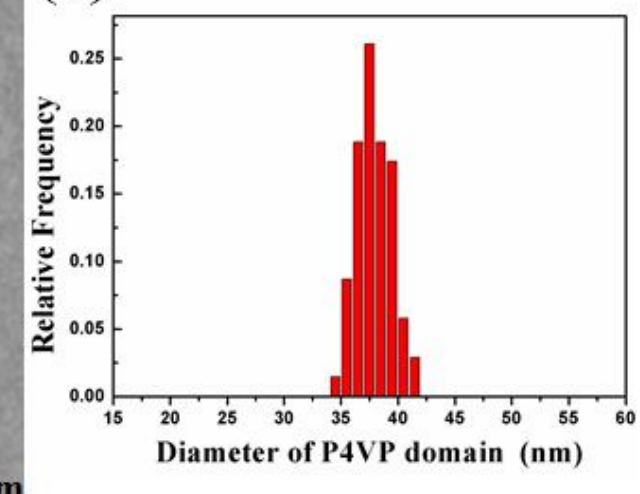

$\underline{200 \mathrm{~nm}}$

Figure S1. (a-c) SEM images of $\mathrm{PS}_{27 \mathrm{k}}-b-\mathrm{P}_{4} \mathrm{VP}_{17 \mathrm{k}}$ sheets from the three-dimensional confined self-assembly in chloroform droplet emulsified with aqueous solution containing $1.2 \mathrm{wt} \% \mathrm{CTAB}$. The initial concentration of $\mathrm{PS}_{27 \mathrm{k}}-b-\mathrm{P}_{4} \mathrm{VP}_{17 \mathrm{k}}$ is $0.5 \mathrm{wt} \%$ in chloroform. (d) Size distribution histogram of cylindrical P4VP domains is obtained from the statistics of 100 samples by TEM analysis software. 


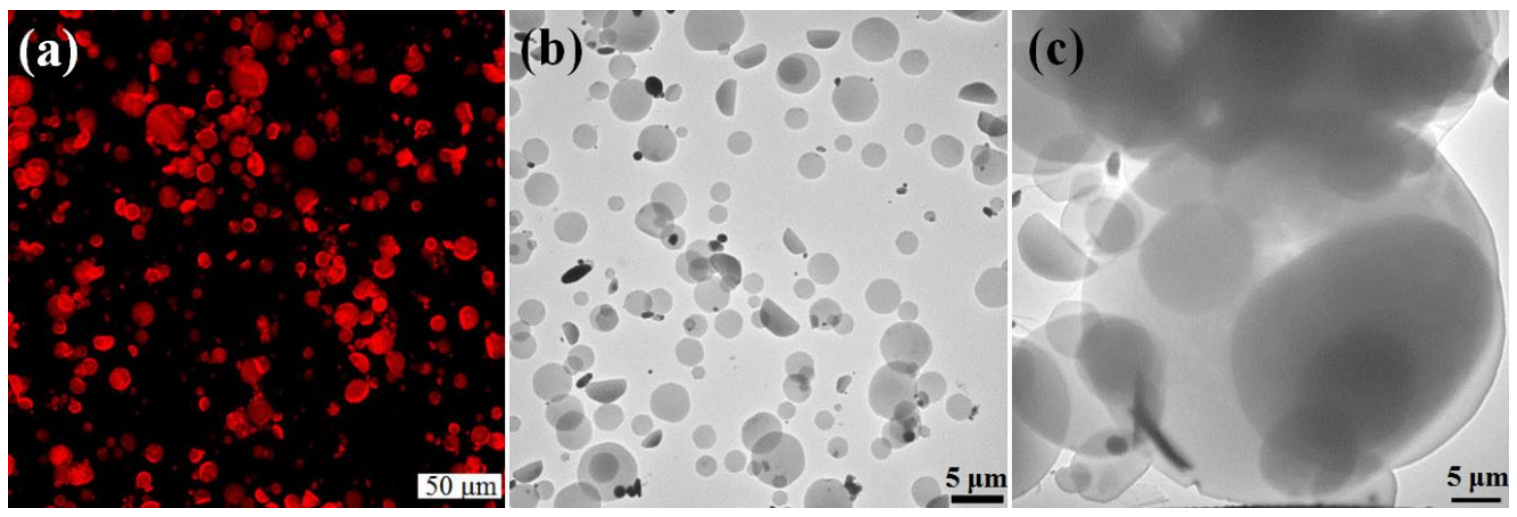

Figure S2. (a) Fluorescence microscopy image of 0.05 wt $\%$ Nile Red loaded $\mathrm{PS}_{27 \mathrm{k}}-b-\mathrm{P} 4 \mathrm{VP}_{17 \mathrm{k}}$ particles. (b, c) TEM images of the $\mathrm{PS}_{27 \mathrm{k}}-b-\mathrm{P} 4 \mathrm{VP}_{17 \mathrm{k}}$ sheets under low magnification.

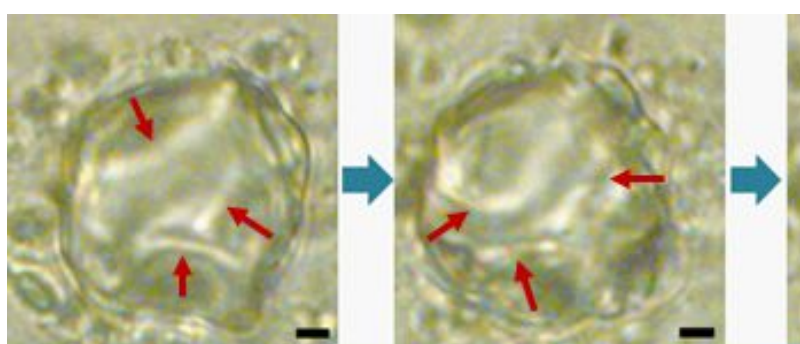

Rugged surface of emulsion droplet

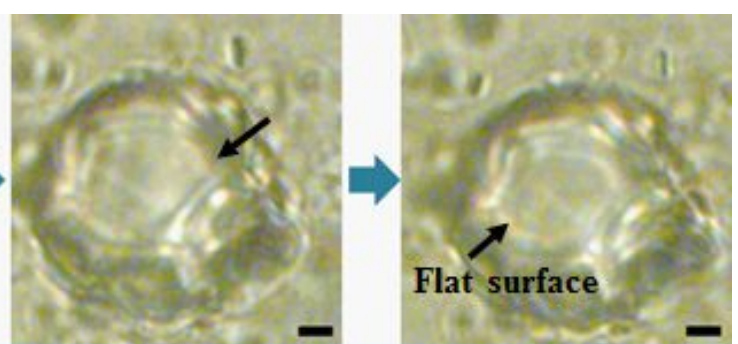

Collapse and flattening of droplet

Figure S3. Optical microscopy images showing the collapse of emulsion droplet in a vertical direction under high content of CTAB (1.2 wt $\%)$ in aqueous solution with the evaporation of the emulsion droplet. The red arrows point to the rugged wrinkles on the surface of the emulsion droplet, while the black arrows point to the flat surface generated by the collapse of the droplets. All the scale bars are $5 \mu \mathrm{m}$. 

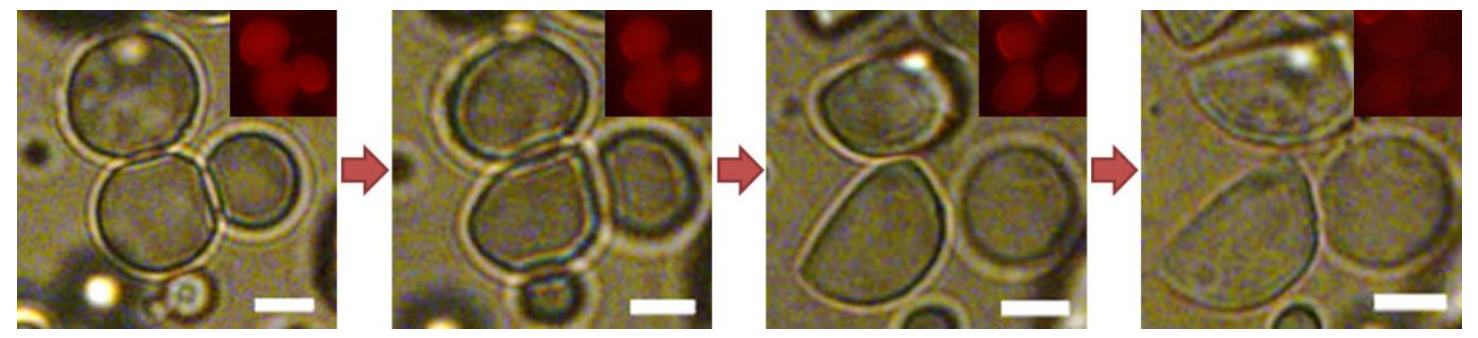

Figure S4. Optical microscopy images showing the evaporation process from squashed emulsions to the glassy $\mathrm{PS}_{27 \mathrm{k}}-b-\mathrm{P}_{4} \mathrm{VP}_{17 \mathrm{k}}$ particles with the evaporation of the emulsion droplets. The concentration of BCPs within the emulsion droplets is $0.5 \mathrm{wt} \%$. The upper right insets are the corresponding fluorescence microscopy images of the emulsion droplets loaded with $0.05 \mathrm{wt} \%$ Nile Red. All the scale bars are $5 \mu \mathrm{m}$.

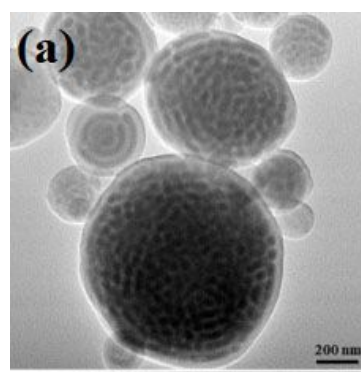

(b)
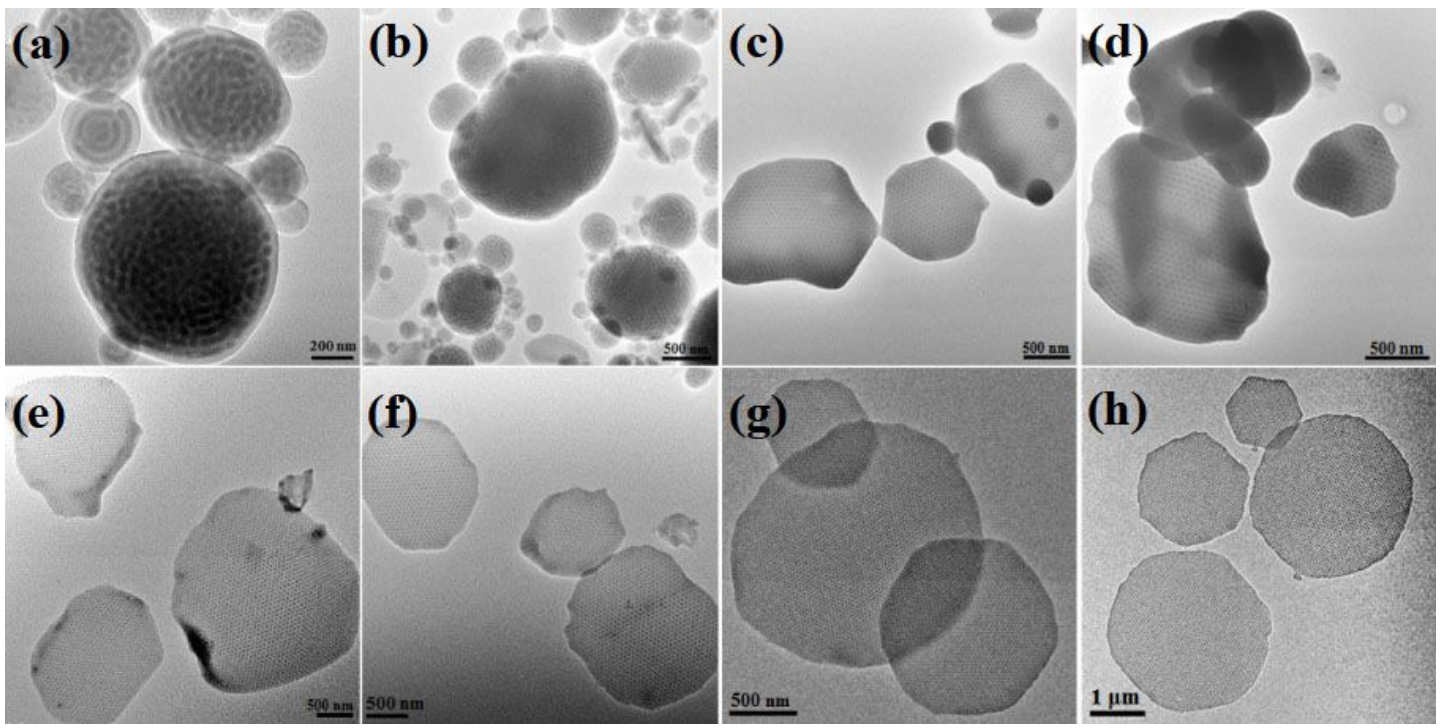

Figure S5. TEM images of $\mathrm{PS}_{27 \mathrm{k}}-b-\mathrm{P} 4 \mathrm{VP}_{17 \mathrm{k}}$ particles emulsified with different concentrations of CTAB surfactant: (a) $0.1 \mathrm{mg} / \mathrm{mL}, \gamma=11.3 \mathrm{mN} / \mathrm{m}$; (b) $0.5 \mathrm{mg} / \mathrm{mL}, \gamma=9.3$ $\mathrm{mN} / \mathrm{m}$; (c) $1 \mathrm{mg} / \mathrm{mL}, \gamma=8.5 \mathrm{mN} / \mathrm{m}$; (d) $2 \mathrm{mg} / \mathrm{mL}, \gamma=7.2 \mathrm{mN} / \mathrm{m}$; (e) $3 \mathrm{mg} / \mathrm{mL}, \gamma=6.3$ $\mathrm{mN} / \mathrm{m}$; (f) $6 \mathrm{mg} / \mathrm{mL}, \gamma=5.6 \mathrm{mN} / \mathrm{m}$; (g) $9 \mathrm{mg} / \mathrm{mL}, \gamma=4.3 \mathrm{mN} / \mathrm{m}$; (h) $12 \mathrm{mg} / \mathrm{mL}, \gamma=3.2$ $\mathrm{mN} / \mathrm{m}$. 


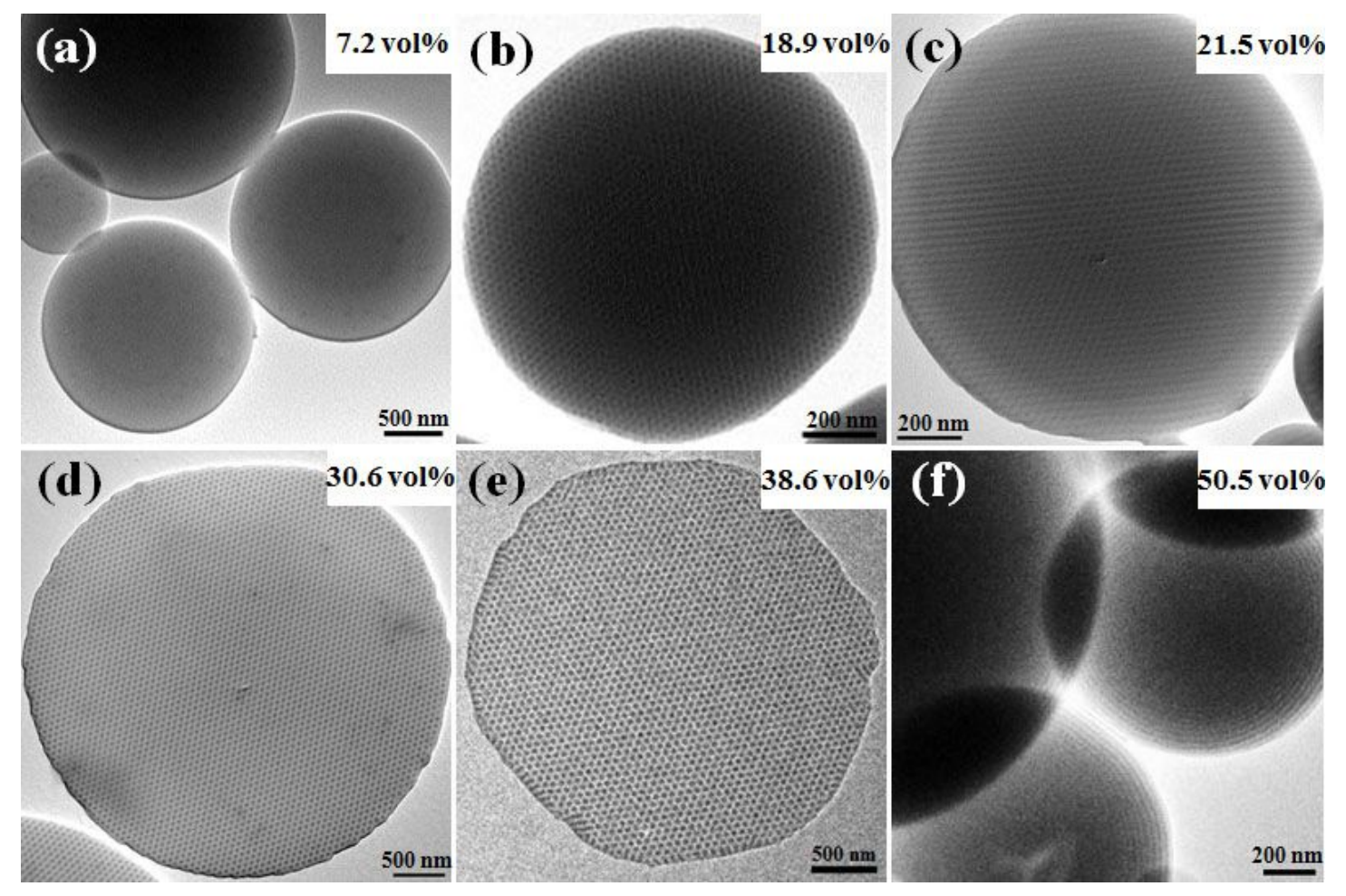

Figure S6. The TEM images of the polymer particles fabricated from PS- $b$-P4VP with different volume fraction of P4VP blocks. (a) $\mathrm{PS}_{35 \mathrm{k}}-b-\mathrm{P}_{\mathrm{VP}} .7 \mathrm{k}, 7.2 \mathrm{vol} \%$; (b) $\mathrm{PS}_{15 \mathrm{k}}-b-\mathrm{P} \mathrm{VP}_{3.5 \mathrm{k}}, 18.9$ vol\%; (c) $\mathrm{PS}_{19 \mathrm{k}}-b-\mathrm{P}_{\mathrm{V}} \mathrm{VP}_{5.2 \mathrm{k}}, 21.5 \mathrm{vol} \%$; (d) $\mathrm{PS}_{48.4 \mathrm{k}}-b-\mathrm{P}_{\mathrm{VP}} \mathrm{VP}_{21.3 \mathrm{k}}$, 30.6 vol\%; (e) $\mathrm{PS}_{27 \mathrm{k}}-b-\mathrm{P}_{4 \mathrm{VP}_{17 \mathrm{k}}}, 38.6$ vol\%; (f) $\mathrm{PS}_{9.8 \mathrm{k}}-b-\mathrm{P} 4 \mathrm{VP}_{10 \mathrm{k}}, 50.5$ vol\%. 


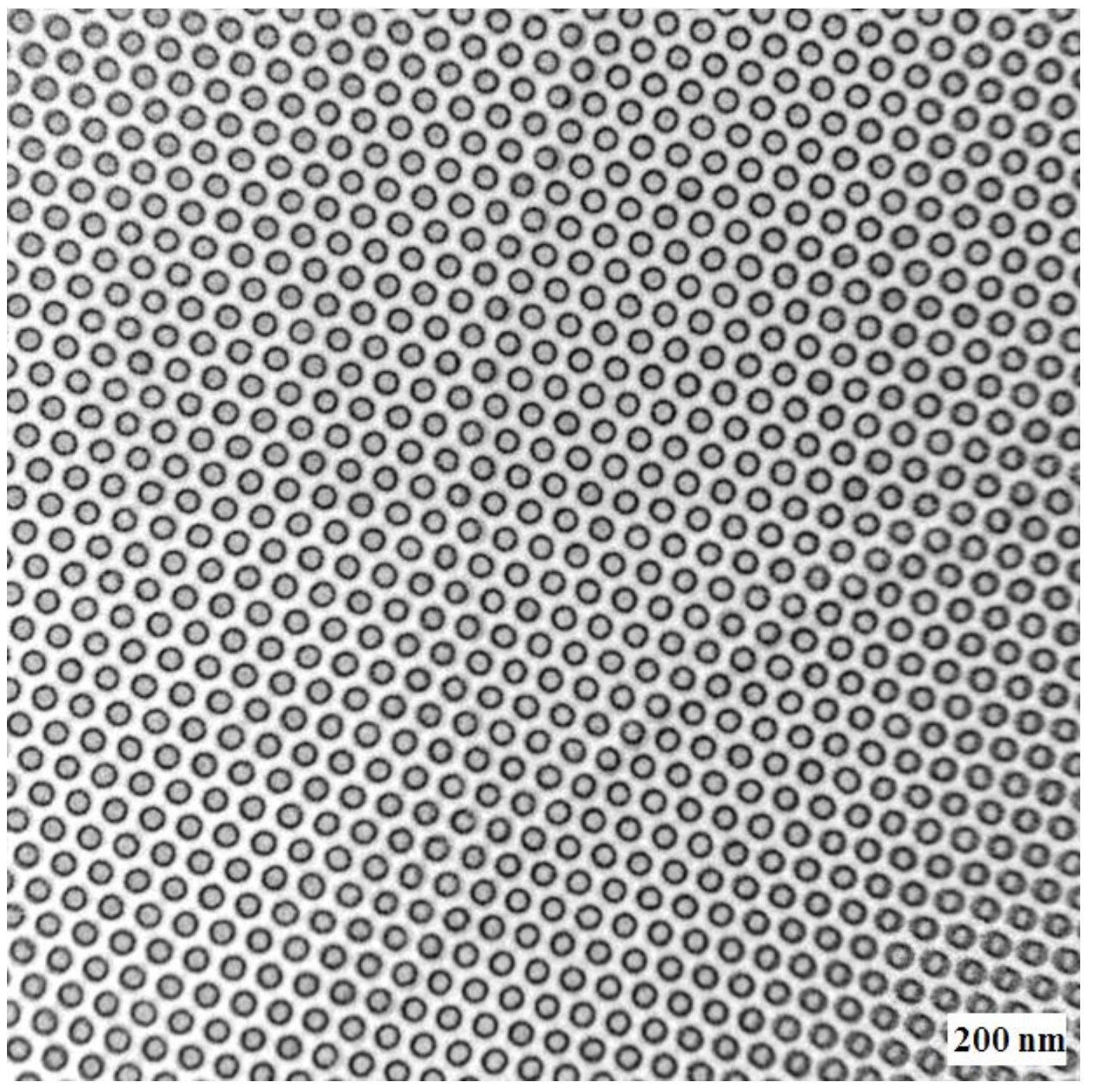

Figure S7. TEM image of the highly ordered ring-like $\mathrm{Au}$ arrangement on the

$\mathrm{PS}_{27 \mathrm{k}}-b-\mathrm{P}_{4} \mathrm{VP}_{17 \mathrm{k}}$ scaffold via adsorption of $5 \mathrm{mM} \mathrm{HAuCl}_{4} \cdot 3 \mathrm{H}_{2} \mathrm{O}$ aqueous solution in 0.05

$\mathrm{wt} \% \mathrm{PS}_{27 \mathrm{k}}-b-\mathrm{P} 4 \mathrm{VP}_{17 \mathrm{k}}$ sheet-like particle suspension for $24 \mathrm{~h}$. 


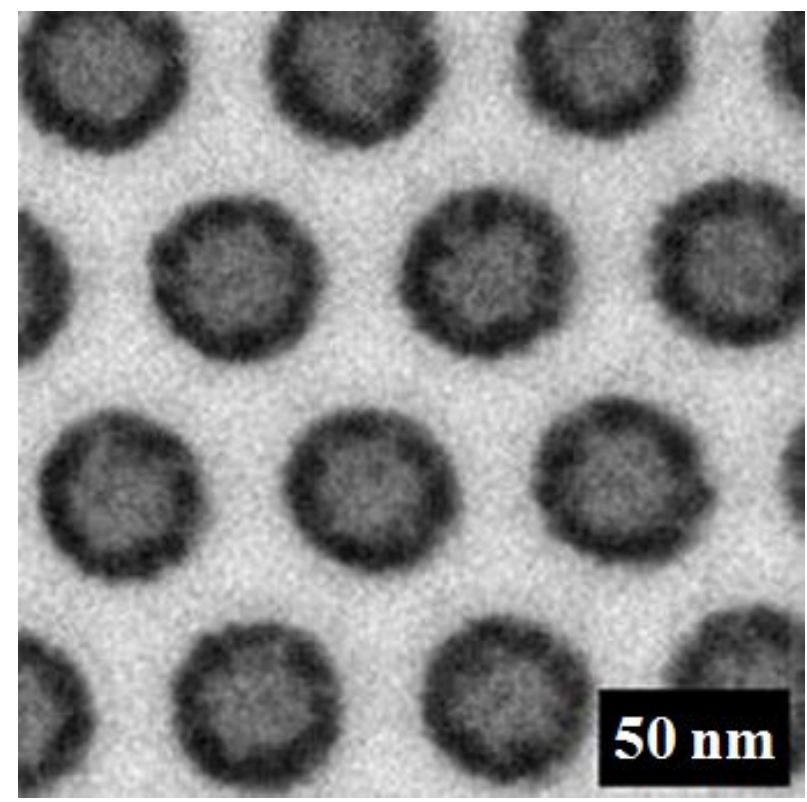

Figure S8. TEM image with High magnification of the hybrid $\mathrm{Au} / \mathrm{PS}_{27 \mathrm{k}}-b-\mathrm{P} 4 \mathrm{VP}_{17 \mathrm{k}}$ nanorings after staining the P4VP domain with iodine vapor. The cylindrical P4VP domains appear darker than PS domain.

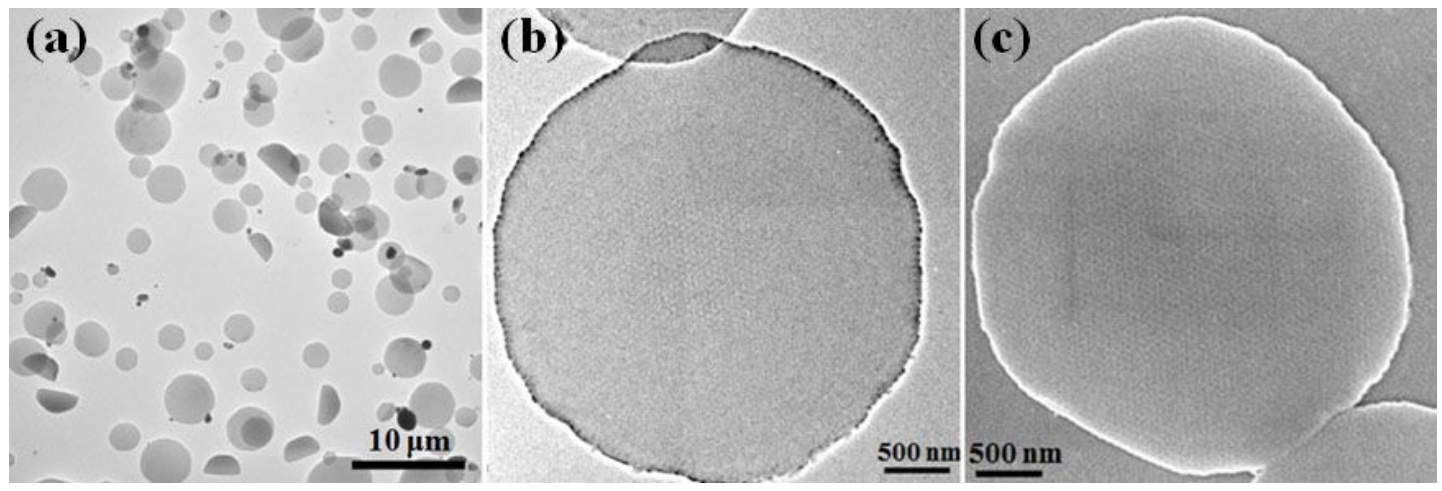

Figure S9. (a) TEM image with low magnification showing the sheet-like $\mathrm{PS}_{27 \mathrm{k}}-b-\mathrm{P} 4 \mathrm{VP}_{17 \mathrm{k}} / \mathrm{AuNPs}$ particles. The PS-tethered AuNPs $(\sim 8.2 \mathrm{vol} \%$, the volume fraction of $\mathrm{Au}_{1.7} \mathrm{~S}$ to the sum of $\mathrm{Au}_{1.7} \mathrm{~S}$ and $\mathrm{PS}_{27 \mathrm{k}}-b-\mathrm{P} 4 \mathrm{VP}_{17 \mathrm{k}}$ ) were added to the $\mathrm{PS}_{27 \mathrm{k}}-b-\mathrm{P} 4 \mathrm{VP}_{17 \mathrm{k}}$ chloroform solution $(0.5 \mathrm{wt} \%)$ and emulsified in the $1.2 \mathrm{wt} \% \mathrm{CTAB}$ aqueous solution. High mag TEM (b) and SEM (c) image of a single $\mathrm{PS}_{27 \mathrm{k}}-b-\mathrm{P} 4 \mathrm{VP}_{17 \mathrm{k}} / \mathrm{AuNPs}$ hybrid particles. 

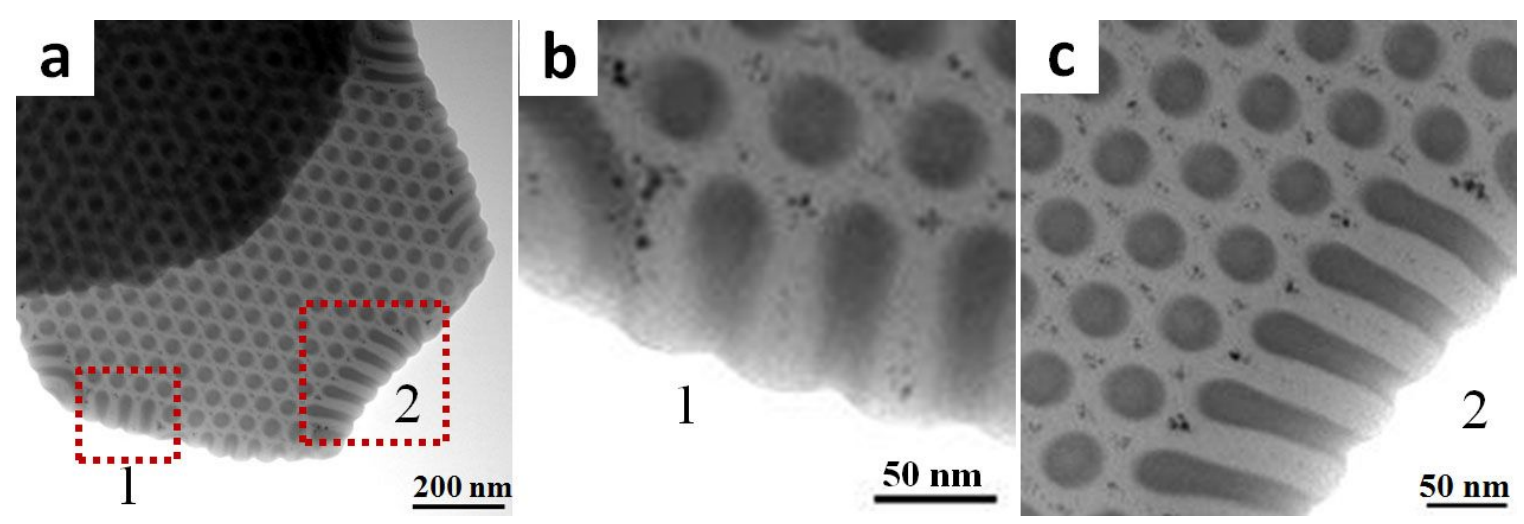

Figure S10. TEM images of two typical lateral position of the hybrid $\mathrm{AuNPs} / \mathrm{PS}_{27 \mathrm{k}}-b-\mathrm{P}_{4} \mathrm{VP}_{17 \mathrm{k}}$ particles.
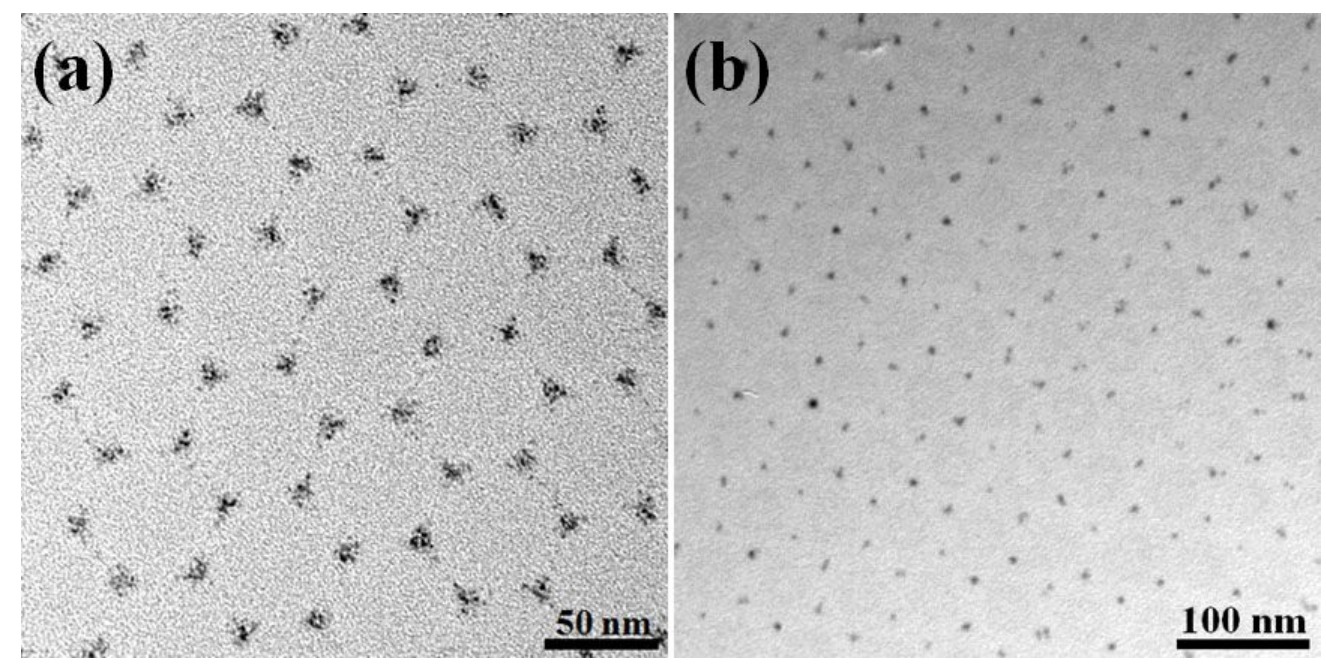

Figure S11. TEM images of blends of $\mathrm{PS}_{27 \mathrm{k}}-b-\mathrm{P}_{4} \mathrm{VP}_{17 \mathrm{k}}$ and PS-tethered AuNPs with different core diameters: (a) A blend of $\mathrm{PS}_{27 \mathrm{k}}-b-\mathrm{P}_{4} \mathrm{VP}_{17 \mathrm{k}}$ and $\mathrm{Au}_{1.7} \mathrm{~S}$ NPs, where the AuNPs aggregated into hexagonal clusters. (b) A blend of $\mathrm{PS}_{27 \mathrm{k}}-b-\mathrm{P}_{4} \mathrm{VP}_{17 \mathrm{k}}$ and $\mathrm{Au}_{3.5} \mathrm{~S}$ NPs, where the AuNPs mainly presented the single distribution. 


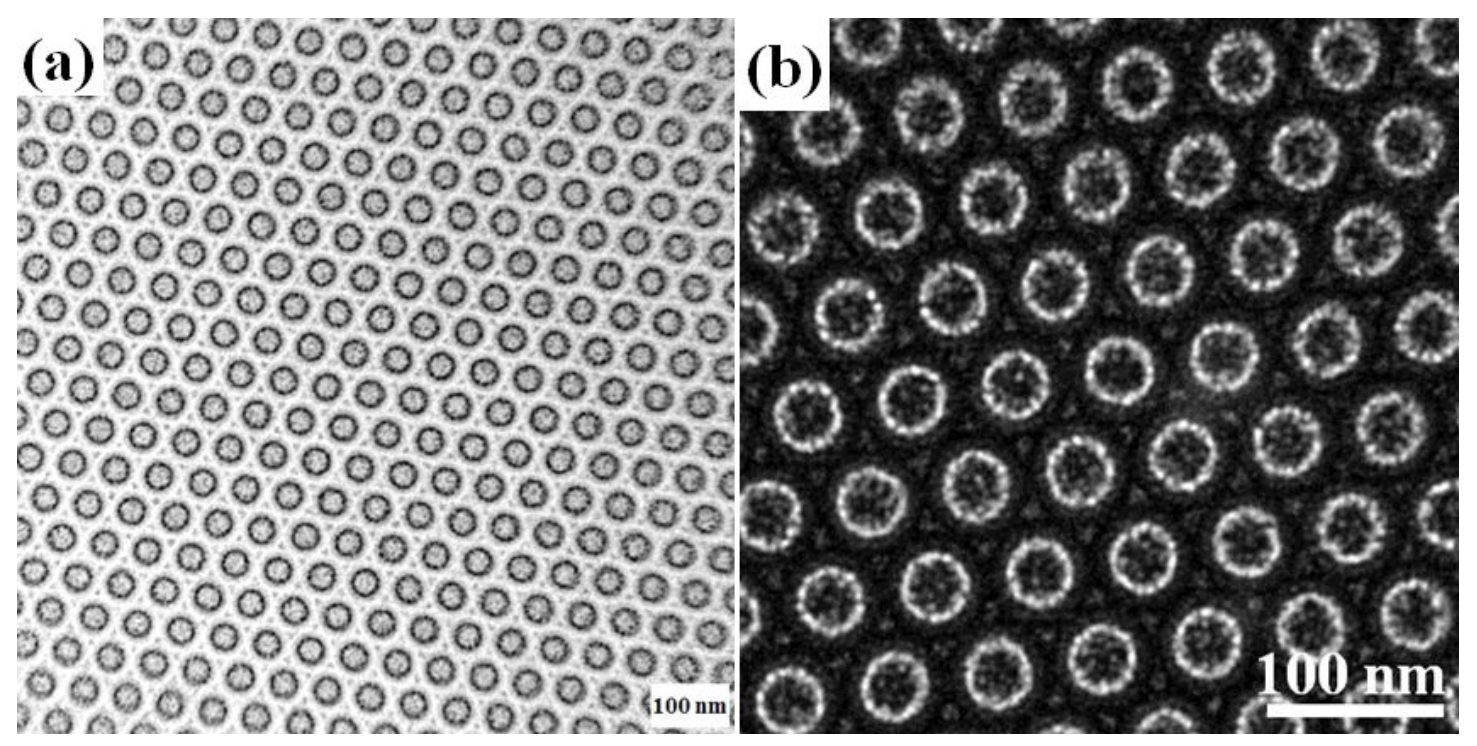

Figure S12. TEM image (a) and the corresponding STEM image (b) of the "benzene ring" pattern on the $\mathrm{PS}_{27 \mathrm{k}}-b-\mathrm{P} 4 \mathrm{VP}_{17 \mathrm{k}}$ scaffold. These "benzene ring" patterned particles were fabricated using $\mathrm{PS}_{27 \mathrm{k}}-b-\mathrm{P} 4 \mathrm{VP}_{17 \mathrm{k}}$ sheet contained graphene-like array of $\mathrm{Au}_{1.7} \mathrm{~S} \mathrm{NPs}$ as the scaffold to in-situ deposit Au precursors.

Table S1. The interfacial tension of the chloroform solution containing PS or P4VP homopolymers at varied CTAB concentrations.

\begin{tabular}{ccc}
\hline $\begin{array}{c}\text { The concentration of CTAB } \\
(\mathrm{mg} / \mathrm{mL})\end{array}$ & $\gamma_{\mathrm{PS} / \mathrm{CTAB}(\mathrm{mN} / \mathrm{m})}$ & ) \\
\hline 0.1 & $17.7 \pm 0.5$ & $7.9 \pm 0.1$ \\
2.0 & $6.0 \pm 0.3$ & $4.9 \pm 0.2$ \\
12.0 & $2.9 \pm 0.2$ & $2.8 \pm 0.2$ \\
\hline
\end{tabular}


Table S2. The characterization of the ligands-coated AuNPs.

\begin{tabular}{ccc}
\hline $\mathrm{AuNPs}$ & $w_{\text {PS }}$ & $w_{\text {Au }}$ \\
\hline $\mathrm{Au}_{1.7} \mathrm{~S}$ & 0.7 & 0.3 \\
\hline
\end{tabular}

Note: The weight fraction of PS ligands $\left(w_{\mathrm{PS}}\right)$ on the AuNPs is measured by thermal gravimetric analysis (TGA), while $w_{\mathrm{Au}}\left(w_{\mathrm{Au}}=1-w_{\mathrm{PS}}\right)$ is the weight fraction of AuNPs cores. The density of AuNPs, PS and P4VP are $19.3 \mathrm{~g} / \mathrm{cm}^{2}, 1.05 \mathrm{~g} / \mathrm{cm}^{2}$ and $1.15 \mathrm{~g} / \mathrm{cm}^{2}$. The mass of PS ( $\left.m_{\mathrm{PS}}\right)$ and P4VP $\left(m_{\mathrm{P} 4 \mathrm{VP}}\right)$ blocks are calculated from the molecular weight of the $\mathrm{PS}_{27 \mathrm{k}}-b-\mathrm{P} 4 \mathrm{VP}_{17 \mathrm{k}} \cdot m_{\mathrm{AuNPs}}$ is the mass of the introduced AuNPs. The volume fraction of PS-coated AuNPs can be calculated by equation S1:

$$
\Phi_{\text {AuNP-PS }}=\frac{\frac{m_{A u N P S} \times w_{P S}}{\rho_{P S}}+\frac{m_{A u N P S} \times w_{A u}}{\rho_{A u}}}{\frac{m_{A u N P S} \times w_{P S}}{\rho_{P S}}+\frac{m_{A u N P_{S}} \times w_{A u}}{\rho_{A u}}+\frac{m_{P S}}{\rho_{P S}}+\frac{m_{P 4 V P}}{\rho_{P 4 V P}}}
$$

